\title{
Note on Dating and Transliteration
}

The Julian calendar (marked "O.S." for "Old Style") was used in Russia until I February 1918, and remains the calendar of the Russian Orthodox Church. On that date, the Gregorian calendar (marked "N.S." for "New Style") was decreed the official calendar, and I February became 14 February 1918. Since the Gregorian calendar had been in use in Europe and America long before 1918, Russians would frequently double-date their letters and diary entries, especially when traveling abroad. To avoid any confusion, in this book dates are specified according to the calendar in use in Russia.

The system of transliteration employed in this book is the system designed by Gerald Abraham for the New Grove Dictionary of Music and Musicians (1980), with the alterations introduced by Richard Taruskin in Musorgsky: Eight Essays and an Epilogue (1993). The principal benefit of the system is that it allows for the consistent representation of adjectival and noun endings. For example, ии, the genitive singular of the noun ending ия, is denoted by $i i$, while ий, the genitive plural, is denoted by $i y$. The Russian letter ы is represented as $i$.

Following Taruskin's example, in the main text I have chosen to use commonly accepted spellings of Russian names and places (e.g. "Scriabin," not "Skryabin"), the sole intentional exception being the replacement of "Tchaikovsky" with "Chaikovsky," a more accurate transliteration in English. I use the surname suffix -sky, as opposed to -skii or -skiy, and omit soft and hard signs. In the bibliographic citations, where adherence to Cyrillic orthography is most useful, the transliteration follows the Abraham system (e.g. "Prokof'yev," not "Prokofiev"). Here, surname suffixes are represented in full, and soft and hard signs retained. 
xii / Note on Dating and Transliteration

Finally, the transliteration of the Preparatory Act libretto in the appendix reflects current Cyrillic spelling, rather than Scriabin's pre-1918 orthography. 